\title{
EVALUATION OF DIFFERENT THERMAL CONDITIONS BASED ON THI UNDER DIFFERENT KIND OF TREE TYPES - AS A SPECIFIC CASE IN ATA BOTANIC GARDEN IN EASTERN TURKEY
}

\author{
M.A. IRMAK \\ S. YILMAZ* \\ H. YILMAZ \\ S. OZER \\ S. TOY
}

\author{
Department of Landscape Architecture \\ Architecture and Design Faculty, Ataturk University \\ 25240, Erzurum, Turkey
}

Received: 08/05/12

*to whom all correspondence should be addressed: Accepted: $19 / 12 / 12$ e-mail: syilmaz_68@hotmail.com

\begin{abstract}
Outdoor recreation is an important issue for people living in areas where they face problems caused by harsh climatic features like the city of Erzurum. The aim of this study was to determine the favourable features of tree species, which can grow in the city, for human bioclimatic comfort conditions. For this aim, measurements of climatic elements (temperature, humidity, and wind) were carried out under different tree canopies in the Ataturk University Ata Botanic Garden in July and August 2008. For the calculation of bioclimatic conditions, one of the most widely used indices, THI (Thermo hygrometric Index) was used based solely on the data of clear and calm days during the measurement period. From the results of the study, it was found that the canopy of Scotch pine trees can provide the most comfortable environment by increasing human thermal condition by $5.1 \%$, followed by Silver birch trees by $3.8 \%$ which increased human thermal condition when compared to open space while mixed canopy did not give the respective results. Some suggestions about the use of plant materials in recreational areas are presented.
\end{abstract}

KEYWORDS: Erzurum, bioclimatic comfort, THI (Thermo hygrometric Index), tree canopy.

\section{INTRODUCTION}

Outdoor recreation is a very important cluster of activities for people who are tired of daily routines and exhausting working conditions. The need for such activities may sometimes be higher in regions, where severe climatic conditions, e.g. long and cold winter conditions are prevailing, like the eastern part of Turkey. Since the time period convenient for outdoor recreation is relatively short in these regions, people who wish to spend their leisure time outdoors should perform their activities in a physically and bio-climatologically comfortable environment. However, because of the constraints of the unfavourable climatic conditions, the number of the activities people can perform and the areas where these activities can take place is quite limited. Mainly picnic activity has to be performed in areas whose quality and quantity are quite inefficient. Main problems of the recreational areas in these regions are lacking of super - and infrastructures in addition to the problems caused by the lack of designing and planning, mainly seen in plantation. Existent recreational areas are not designed for recreational purposes and people generally have to use the areas, which were designed inappropriately and where aimlessly chosen plant species are growing.

In the assessment of the convenience of a place for tourism and recreational activities, weather and climate along with topographical and orographical conditions, vegetation and fauna do not only play a defining role but they are also limiting and controlling factors over them (Rudel et al., 2007). Climatic parameters such as monthly means of maximum daily temperature, mean daily temperature, minimum daily relative humidity, mean daily relative humidity, total precipitation, total 
hours of sunshine, average wind speed and global radiation are accepted to be effective on recreation activities (Fanger, 1970; Scott et al., 2004). The aforementioned climatic elements can affect recreational activities either individually or in a combined way. Although the individual effects of these elements are sometimes forefront, their combined effects are more dominant on people for their health status and work performance as well as their pleasure and the quality of experience taken from recreational activities. Among the climatic elements, which may be accepted to be the most influential factors on human outdoor activities, temperature and its effect so called "thermal effect" is in the first row. Since this element affects and is affected by all other parameters, it embodies their combined effects together with its direct effect on people performing work or leisure activities outdoors. Thermal effect determines the comfort of people outdoors together with other factors e.g. clothing and working load. In this respect, the effect of thermal conditions on humans is termed with thermal comfort. Thermal comfort is defined as the condition of mind that expresses satisfaction with the thermal environment (ASHRAE, 1992). Thermal comfort has very important effects on people performing outdoor recreation activities. Since its effects are directly seen on human psychology, it has been accepted as an influential factor on man's intellectual, manual and perceptual performance.

Plant materials, especially trees, are an indispensable part of landscape designs and projects. Their vitality for humans and their thermal comfort in various environments are very well and thoroughly documented in the literature (e.g. mainly by the Chicago Urban Forest Project, McPherson et al., 1994; Simpson et al., 1994; Honjo and Takakura, 1990; Canton et al., 1994; Taha, 1997; Bruse and Fleer, 1998; Scott et al., 1999; Shashua-Bar and Hoffman, 2000; Heisler and Wang, 2002; Streiling and Matzarakis, 2003; Ali-Toudert and Mayer, 2007; Toy et al., 2007). Differences in climatic elements between tree canopy and open spaces have been detected at various rates (Myrup et al., 1993; Simpson et al., 1994; Scott et al, 1999; Streiling and Matzarakis, 2003; Yilmaz et al., 2007, Toy and Yilmaz, 2010). Effects of tree covers on human climatic and bioclimatic environment can occur in two different mechanisms mainly by directly shading the ground surface and indirectly by supplying humidity (Lee, 1978; Oke, 1987). Because of the favourable effects of tree canopy on human thermal comfort, they should be used very carefully to take their advantages in the landscape planning works especially for recreational areas in the regions with harsh climatic features where relatively less tree species can be grown.

The aim of this study was to try to determine the suitable tree canopy in order to offer bio-climatically more comfortable environments for people performing their recreational activities outdoor by determining human thermal comfort conditions under different covers of the most extensively grown tree species in the study area. For this aim, Thermo hygrometric Index (THI), one of the most densely used bioclimatic indices was used in the calculation of thermal comfort conditions (Unger, 1999; Toy et al., 2007; Toy and Yilmaz, 2010a) using meteorological data measured on 26 calm and clear days of July and August 2008 and at four different points; under the clusters of Silver Birch; Scotch Pine and their mixture and in the open space in the Ata Botanic Garden of Atatürk University, Erzurum

\section{MATERIALS AND METHOD}

This study was conducted in the Ata Botanik garden in the city of Erzurum, which is located in the eastern part of Turkey $\left(39^{\circ} 55^{\prime} \mathrm{N}\right.$ and $\left.41^{\circ} 16^{\prime} \mathrm{E}\right)$ at $1850 \mathrm{~m}$ above sea level on a flat plain surrounded by nearly 2000-m-high mountain ranges (Fig. 1).

According to the census conducted by the Turkish State Statistics Institution, the population of the city is 366,962 (Anonymous, 2002). The city has harsh continental climatic features because it is isolated and far from sea. According to climatic measurements between 1988 and 2008, long term annual mean temperature is $5.1^{\circ} \mathrm{C}$ and the ever recorded maximum and minimum temperatures are $35.6^{\circ} \mathrm{C}$ and $-37.2^{\circ} \mathrm{C}$, respectively. In the same observation period, mean annual rainfall is $413.3 \mathrm{~mm}$; mean annual relative humidity is $63.3 \%$ and mean annual vapour pressure is $6.0 \mathrm{mb}$. Mean yearly wind speed is $2.7 \mathrm{~m} / \mathrm{sec}$ and prevailing wind direction is ENE in summer and WSW in winter due to circulation systems. 


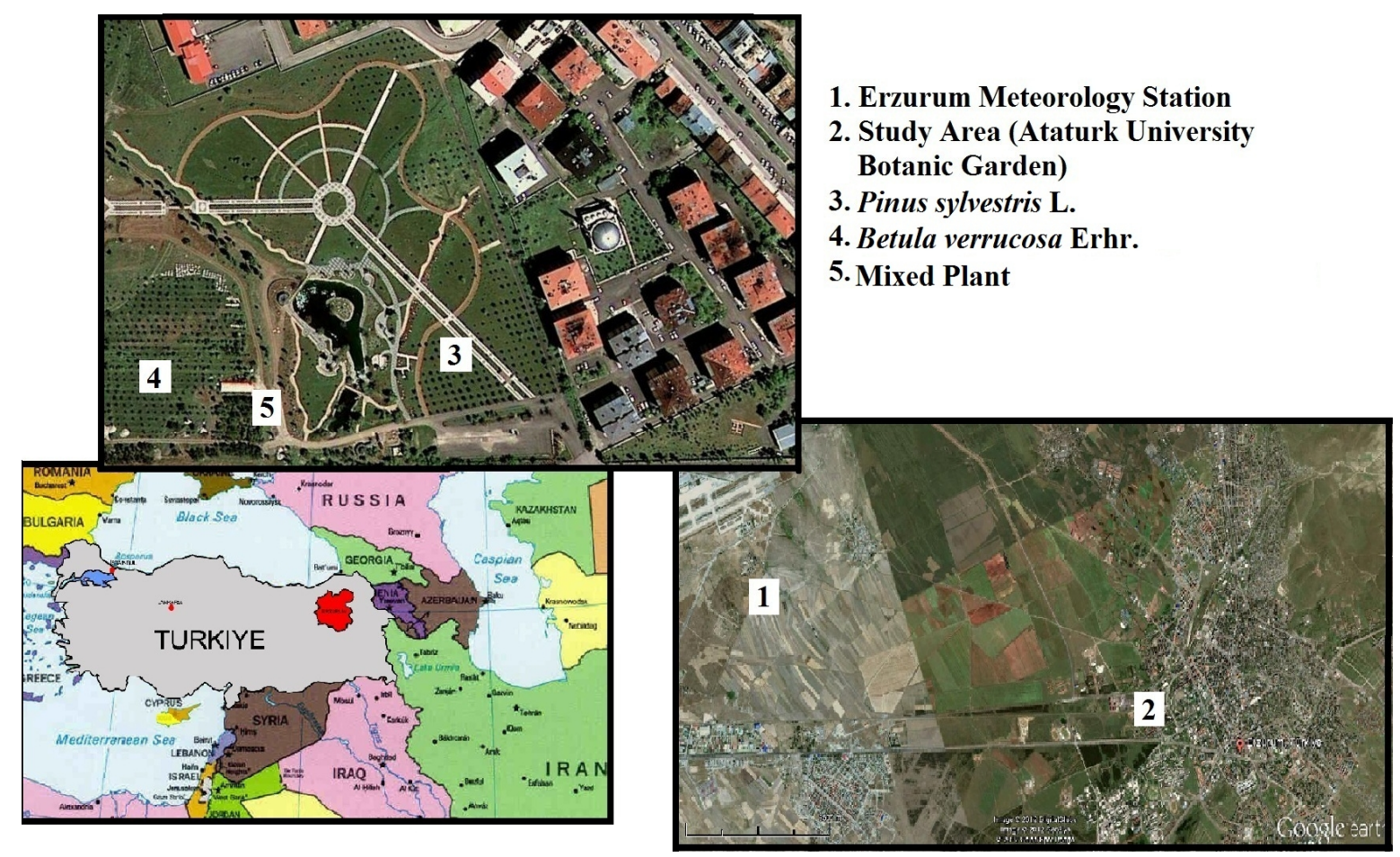

Figure 1. Location map of study area

Even though in the city, long and harsh winters (at least six - month from late October to late April sometimes early May) are prevailing, people are not provided with recreational areas convenient with this condition, except for a ski centre on Palandöken Mount, which is a famous winter sport centre and where local people cannot afford to ski or perform recreational activities. Therefore, local people have to stay in indoor areas during winter period and can perform outdoor recreational activities in only a relatively warm summer period. Due to negative climatic impacts, the number of plant species, especially trees, which can grow naturally or be adapted in green areas, is not much. For instance, in a study (Yilmaz and Irmak, 2004) on the plant materials used in open-green spaces in the city, it was determined that only 13 tree species (e.g. Black locust, Robinia pseudoacacia L; Silver birch, Betula verrucosa Ehrh.; Box elder, Acer negundo L.; Single-seed hawthorn, Crataegus monogyna Jacq.; White Ash (Biltmore ash), Fraxinus americana L.; Sour cherry, Prunus cerasus L.; Oleaster (Russian olive), Eleagnus angustifolia L.; European Ash or (Common Ash), Fraxinus excelsior L.; Weeping Willow, Salix babylonica L.; White poplar, Populus alba L.; Scotch pine, Pinus slyvestris L.; Wych elm, Ulmus glabra 'Huds') are used in these areas. It was also found in the same study that among these tree species the most prevailing and naturally grown species whose maintenance is relatively easy are Silver birch (Betula verrucosa Ehrh.) and Scotch pine (Pinus slyvestris L.). In addition to the problems caused by lack of convenient plants for recreational areas, existing plant materials in the recreational areas are used carelessly and aimlessly.

\section{METEOROLOGICAL DATA}

In order to determine the effect of tree shadows on climatic and bioclimatic conditions, temperature measurements were carried out during the months of July and August 2008 in the property of the Botanical Garden of Atatürk University near the city centre (1840m and $39^{\circ} 55^{\prime} \mathrm{N} ; 4^{\circ} 16^{\prime} \mathrm{E}$ ) under the clusters of 20 year - old Scotch pines (Pinus sylvestris L.); Silver-birches (Betula verrucosa $\mathrm{EHRH}$ ) and their mixture and in the open space.

In the measurement of temperatures, the same measurement standards with the stations operated by Turkish State Meteorological Service were followed. Therefore, data-logger thermometers (Finest Model 345; Fine Instruments Corporation) were calibrated according to thermometers at the meteorological station of the city before beginning the measurements and they were placed at the selected measurement points in a white screened (Stevenson screen) box $2 \mathrm{~m}$ above the ground. Although measurements were conducted daily for 24 hours in July and August months, in order to make a healthy comparison, only the temperature data of the clear and calm days were selected at 
$10.00,13.00$ and $17.00 \mathrm{LT}$, when people are mainly in outdoor areas and can densely perform recreational activities. The number of such days in both months was twenty six (21 in July and 5 in August, which are the hottest months of the year). Means of temperatures were calculated; differences between the means of temperatures under the canopies and in open space were found and trends in temperatures are presented in Figure 2.

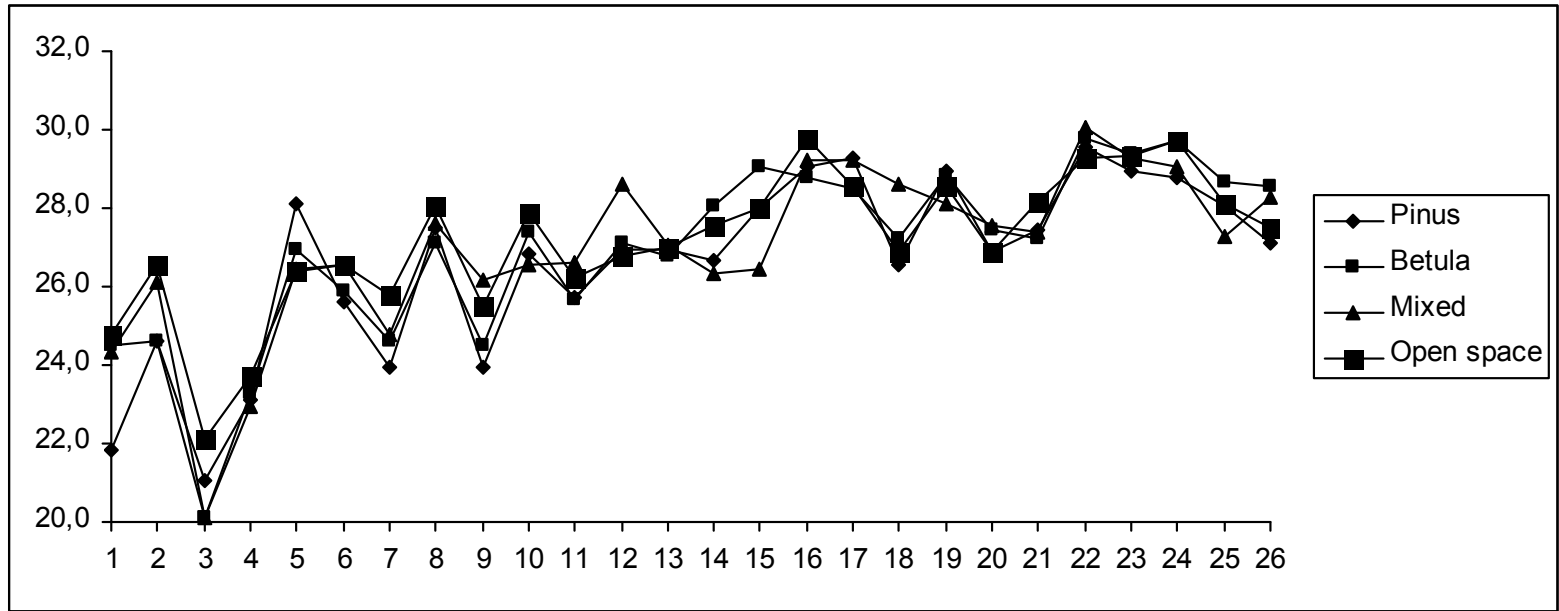

Figure 2. Trends in temperatures measured at selected points

Means of the daily data under canopy types were calculated and statistically compared with the mean temperatures in open space using $t$ and ANOVA tests. According to the results of the statistical analysis, temperature differences between open space and tree canopies were found to be statistically not significant $(p=0.05)$, mean differences from open space were $0.7^{\circ} \mathrm{C}$ for Scotch pines and 0.3 for Silver birches and mixture, respectively and comparable to the values provided in literature (e.g. Oke, 1989; Yilmaz et al., 2007).

\section{CALCULATION OF HUMAN THERMAL COMFORT CONDITIONS}

Today outdoor human thermal comfort conditions are widely defined and calculated using very different approaches (e.g. MEMI, Munich Energy Balance Model for Individuals, Höppe, 1984, 1993; ASHRAE 1992, MENEX - 2005, The Man-ENvironment heat EXchange model, Blazejczyk, 2005), simple and complex calculation indices (e.g. THI, Thermo hygrometric Index, Unger, 1999; PMV, Predicted Mean Vote, Fanger, 1970; PET, Physiologically Equivalent Temperature - Höppe, 1999; and SET*, New Standard Effective Temperature, Gagge et al., 1971) and computerised models (e.g. RayMan; Matzarakis et al., 2000; 2007 and Matzarakis and Rutz, 2005; ENVI-met and dPet, Bruse, 2000; and OUTCOMES, Heisler and Wang, 2002). In spite of the large quantity of thermal comfort calculation indices, they can be classified into two main groups; simple and complex indices, most of which "share many common features". While simple indices, such as THI, take the combined effects of a few meteorological parameters (e.g. air temperature; Ta and relative humidity; $\mathrm{RH}$ ) and "ignore the decisive role of human physiology, activity, clothing and other personal data (height, weight, age, sex), complex indices are more recent, promoted by the lately development of computing techniques, and rely on the human energy balance" (Ali -Toudert, 2005).

In the present study, human thermal comfort conditions were calculated according to one of the most widely used simple bioclimatic indexes; THI (Thermo hygrometric Index or Discomfort Index), which was first developed by Thom (1959) and has been widely used especially in recent studies (e.g. by Unger, 1999; Emmanuel, 2005; Toy et al., 2007; Yilmaz et al., 2007; Antoniou et al., 2008). Although the index seems to be old, it was deliberately chosen to compare thermal comfort conditions under different canopy types. Since this index has the capability of giving direct, rather than predictive, results of thermal comfort conditions relying only on temperature and humidity values practically and conveniently with the measurements, where only temperatures were obtained and relative humidity values were calculated from these values, it could give simple and precise results by which some opinions about the conditions can be gained as in other studies such as Unger, 1999; Toy et al., 2007; Yilmaz et al., 2007, Toy and Yilmaz, 2010 and Antoniou et al., 2008). In fact, before choosing the suitable thermal comfort index, calculations were carried out according to two different indices, 
PET (Physiologically Equivalent Temperature) and THI (Thermo hygrometric Index). At the end of the calculation PET index gave the comfort values far beyond its comfort ranges.

$\mathrm{THI}$ index uses the relative effects of air temperature $(\mathrm{Ta})$ and relative humidity $(\mathrm{RH})$ for the calculation of human thermal comfort conditions, especially under windless conditions and gives the results in Celsius degree (Unger 1999; Yilmaz et al., 2007). It employs a simple linear equation;

$\mathrm{THI}\left({ }^{\circ} \mathrm{C}\right)=t-(0.55-0.0055 f)(t-14.5)$

where $t$ represents air temperature $(\mathrm{Ta})$ and $f$ relative humidity $(\mathrm{RH}$; Unger 1999).

Calculated thermal comfort results are evaluated considering the predetermined categories in a table (Table 1), which classifies the comfort conditions according to human sensation of temperature.

Table 1. The categories of the thermohygrometric index

(THI; Kyle 1994 in Unger 1999)

\begin{tabular}{ll}
\hline THI category & Temperature $\left({ }^{\circ} \mathrm{C}\right)$ \\
\hline Hyper-glacial & $<-40$ \\
\hline Glacial & -39.9 to -20 \\
\hline Extremely cold & -19.9 to -10 \\
\hline Very cold & -9.9 to -1.8 \\
\hline Cold & -1.7 to +12.9 \\
\hline Cool & +13 to +14.9 \\
\hline Comfortable & +15 to +19.9 \\
\hline Hot & +20 to +26.4 \\
\hline Very hot & +26.5 to +29.9 \\
\hline Torrid & $>+30$ \\
\hline
\end{tabular}

Thermal comfort conditions were calculated at three different times of the day $(10.00,13.00$ and $17.00 \mathrm{LT})$ using air temperature $(\mathrm{Ta})$ and relative humidity $(\mathrm{RH})$ values obtained for 26 days. Percentage distribution of comfort categories was calculated for the measurement period.

\section{RESULTS AND DISCUSSION}

From the calculations of thermal comfort calculations, it was found that mean values of THI over three different daytimes under the canopies of pines, birches and their mixture and in open space were $19.8,20.1,20.1$ and $20.3{ }^{\circ} \mathrm{C}$, respectively and no statistical difference was found between them $(p=0.05)$. When considering these means and thermal comfort categories of THI, the only canopy type within the "comfortable" range is pine trees while the rest are in the "hot" range.

In Figure 3, percentage distribution of THI categories according to areas and three different day times are presented. When considered the morning hour $(10.00 \mathrm{LT})$, it can be seen from Figure 3 that prevailing thermal comfort range is "comfortable" for all of three canopy types while in open space "cool" is prevailing. The number of days within "comfortable" range is 9,13 and 10 under pines, birches and their mixture, respectively. This result can show that silver birch canopy may provide thermal comfort conditions in the morning hours more than the other two canopies, where "cold" and "cool" range, that is, cold stress is more effective, because of its weak shadowing effect and since it allows for the sun-light to warm the environment under its canopy. At this hour, "cool" range is prevailing in the open space due to severe solar radiation loss.

For the noon hour $(13.00 \mathrm{LT})$, which was accepted to be the hottest point of the day, prevailing comfort range was found to be "hot". The number of days is 16,18, 18 and 18 for pines, bitches, mixture and open space, respectively. For all measurement points, the second prevailing comfort range is "comfortable" and the number of days is $8,6,5$ and 6 in the same order as before. From those results, it can be deduced that at the warmest time point of the day the most favourable canopy type is pine trees since it has the least and the highest "hot" and "comfortable" range numbers respectively, due to its dense leaf area and more shadowing effect. 


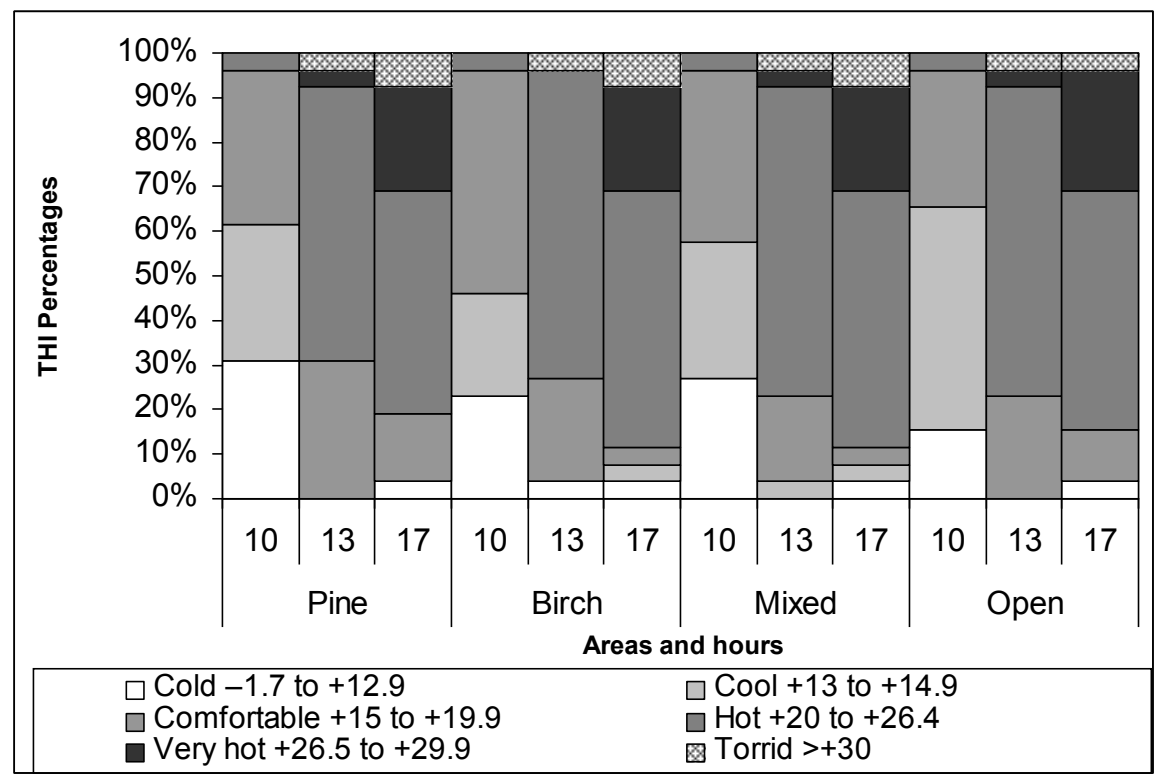

Figure 3. Distribution of $\mathrm{THI}$ categories for the areas and day times

When considering the evening hour (17.00 LT), it is interesting that prevailing comfort range is "hot" again for all the areas. The number of days is $13,15,15$ and 14 for pines, birches, mixture and open space for this comfort range. This condition may have been caused by the effect of sunlight, which may still actively warm the environment under canopies from a reverse angle. This result might have been different if another later hour had been selected for the evaluation. However, it is at this hour that people prefer to perform their recreational activities. The second prevailing comfort range at this hour is the "very hot" range which was seen on 6 days under all canopies and 7 days in the open space while the "comfortable" range is only the third range for the areas with the number of days 4 , 1,1 and 3 in the same order. This result is interesting because while the pine canopy shows the highest "comfortable" range number at this hour, which is expected due to its resistance to sun light, the open space shows the second highest "comfortable" range number, which may be attributed to rapid solar radiation loss.

In the study, another analysis was conducted using the 24-hour THI values and estimating their percentage distributions. Results of the percentage distribution of THI categories over 624 hours (24 hours of 26 measurement days) are presented in Table 2.

Table 2. Hourly distribution of THI categories in percentage

\begin{tabular}{lllll}
\hline $\begin{array}{l}\text { THI categories / Canopy } \\
\text { Types }\end{array}$ & Pine (\%) & Birch (\%) & Mixed (\%) & Open (\%) \\
\hline Cold -1.7 to +12.9 & 11.5 & 10.3 & 10.3 & 6.4 \\
\hline Cool +13 to +14.9 & 10.3 & 9.0 & 12.8 & 16.7 \\
\hline Comfortable +15 to +19.9 & 26.9 & 25.6 & 20.5 & 21.8 \\
\hline Hot +20 to +26.4 & 38.5 & 43.6 & 43.6 & 42.3 \\
\hline Very hot +26.5 to +29.9 & 9.0 & 7.7 & 9.0 & 10.3 \\
\hline Torrid $>+30$ & 3.8 & 3.8 & 3.8 & 2.6 \\
\hline Total & 100 & 100 & 100 & 100 \\
\hline
\end{tabular}

According to Table 2, the highest percentage of "comfortable" range is seen under pine trees while the second highest percentage belongs to birch canopy. Mixed canopy couldn't give the expected result and in this environment "comfortable" conditions are less than in the open space, which have been resulted from various situations, e.g. selection of the measurement point or development of trees. The most prevailing comfort range at all the points is "hot" since the selected measurement period is the hottest time of the year in the region. From all the results, it can be said that canopy of Scotch pine trees can provide the most comfortable environment by increasing human thermal 
condition by $5.1 \%$, followed by Silver birch trees which increased human thermal comfort conditions by $3.8 \%$ compared to the open space while mixed canopy could not give the expected results.

Due to countless benefits of outdoor recreational activities to human psychology, health and work performance people should perform these activities in comfortable environments both infrastructurally and bio-climatically. For better planning and management of landscape units such as forests for recreational purposes there is need for not only to give much emphasis to the visual aesthetic aspects, but also to understand the microclimate differences among vegetative units and their influence on recreation-seeking humans (Schiller, 2001). In this respect, many studies evaluating the contributions of plant materials to human thermal comfort are present in the related literature. For instance, Schiller (2001) conducted a study in Israel over man-made and natural forests, some neglected and some regularly used for recreation using the sweating rate index $(S)$ and found that summer thermal comfort is directly related to tall tree forest canopy closure, which can be supported by the present study since Scotch pine trees are taller than the Birches. In another study carried out in Freiburg (Germany), (Streiling and Matzarakis, 2003), the effects of single and small clusters of horse chestnut trees (Aesculus hippocastanum) on the bio-climate of a city were examined using PET (Physiologically Equivalent Temperature) and Tmrt (mean radiation temperature) and it was found that distinct differences between areas with trees and areas without trees are present. The results of the aforementioned study are in agreement with the present study although the used thermal indices are different and the differences between the areas in the present study are not quite large due to the fact that it was not conducted in the urban area. In other recent studies, it has again been shown that vegetation is beneficial in lowering air temperatures, in providing shade and in improving thermal comfort (Spangenberg et al., 2008). Shashua-Bar and Hoffman (2004) found air temperatures in Tel-Aviv, Israel, in tree planted streets to be $1-2.5^{\circ} \mathrm{C}$ lower than in non-vegetated streets at the hottest part of the day (15:00 h). Chatzidimitriou et al. (2005) in Thessaloniki, Greece, found air temperature decrease for tree-aligned streets to be less than $1^{\circ} \mathrm{C}$, but up to $20^{\circ} \mathrm{C}$ lower surface temperatures and more than $40^{\circ} \mathrm{C}$ lower mean radiant temperatures applying the simulation software ENVI-met. In the hot dry climate of Ghardaia, Algeria, Ali- Toudert and Mayer (2007) found that shading trees could improve the thermal comfort in streets considerably. In another simulation study of different greening scenarios using ENVI-met in Rio de Janeiro, Brazil, Spangenberg (2004) found that an increased amount of urban green (tree cover of $30 \%$ of the ground and $100 \%$ green roofs) could nearly re-create the comfortable conditions of a natural forest. Toy et al (2007) in the same study area (Erzurum, Turkey) showed using the same bioclimatic index (THI) that in urban forest area of Scotch pine trees "comfortable" range was $10 \%$ of the 10- month study period. Spangenberg et al. (2008) found in the city centre of São Paulo, Brazil that urban park was up to $2^{\circ} \mathrm{C}$ cooler than city square and street canyon and they simulated their measurement day using the numerical model ENVI-met and showed that incorporating street trees in the urban canyon had a limited cooling effect on the air temperature (up to $1.1^{\circ} \mathrm{C}$ ), but led to a significant cooling of the street surface (up to $12^{\circ} \mathrm{C}$ ) as well as a great reduction of the mean radiant temperature at pedestrian height (up to $24^{\circ} \mathrm{C}$ ). It can be seen from recent studies that the extents of thermal and thermal comfort differences between tree - planted and naked areas are changing depending on the measurement sites, measurement hours and used bioclimatic indices; however, the results of these studies have almost been the same which shows the favourable contribution of trees to human comfort in thermal environment and this finding was reconfirmed by the present study. Another important aspect of the present study is that it was conducted to evaluate the contributions of distinct tree species to thermal environment with direct measurement and direct thermal comfort calculation rather than simulation or use of predictive models e.g. Envi-met or RayMan. Therefore, more concrete and realistic values and evaluation could be made in the present study.

\section{CONCLUSION}

In the present study, Scotch pine trees, which are the native plants of the study area, were found to provide thermally most comfortable environments in harsh continental climates, like the one in the study area. Therefore, in planning recreational areas, responsible people should consider the results obtained from this study and the quantity and quality of such studies should be improved since outdoor recreation is of vital importance in such regions, where very short outdoor recreation period is experienced by locals. 


\section{REFERENCES}

Ali-Toudert F. (2005), Dependence of Outdoor Thermal Comfort on Street Design in Hot and Dry Climate. (Dissertation), Ber. Meteor. Inst. Univ. Freiburg Nr. 15, 224 p.

Ali-Toudert F. and Mayer H. (2007), Effects of asymmetry, galleries, overhanging facades and vegetation on thermal comfort in urban street canyons, Solar Energy, 81, 742-754.

Anonymous (2002), Social and Economic Quantities of Census in 2000. Turkish State Statistics Institution, ISBN 975-19-3086-3, Publication No: 2684, Ankara.

Antoniou A., Larissi I., Maitos A. and Paliatsos A.G. (2008), Case studies on discomfort levels in different regions in Athens, Greece, International Scientific Conference SynEnergy Forum (S.E.F.) The conference for International Synergy in Energy, Environment, Tourism and Information Technology. II. Energy/ Environment II Session 4. Spetses, Greece 28-31 May 2008, 8 pp.

ASHRAE (American Society of Heating, Refrigerating and Air Conditioning Engineers) (1992), Thermal environmental conditions for human occupancy. ANSI/ASHRAE standards, Atlanta

Blazejczyk K. (2005), New indices to assess thermal risks outdoors. In: I. Holmér, K. Kuklane, Ch. Gao (ed.), Environmental Ergonomics XI, Proc. of the $11^{\text {th }}$ International Conference, 22-26 May, 2005 Ystat, Sweden, 222-225 pp.

Bruse M., and Fleer H. (1998), Simulating surface-plant-air interactions inside urban environments with a three dimensional numerical model, Environmental Modelling and Software, 13, 373-384.

Bruse M. (2000), Assessing thermal comfort in urban environments using an integrated dynamic microscale bio-meteorological model system, $3^{\text {rd }}$ Symp. on the Urban Environ., Davis, CA, Am. Meteorol. Soc. $159-160$.

Canton M.A., Cortegoso J.L. and De Rosa C. (1994), Solar permeability of urban trees in cities of western Argentina, Energy and Buildings, 20, 219-230.

Chatzidimitriou, A., Chrissomallidou N. and Yannas S. (2005), Microclimate modifications of an urban street in northern Greece. In: PLEA 2005 - Passive and Low Energy Architecture, 2005, Beirut. Proceedings PLEA 2005 - Passive and Low Energy Architecture, Beirut: PLEA International, 689$694 \mathrm{pp}$.

Emmanuel R. (2005), Thermal comfort implications of urbanization in a warm-humid city: the Colombo Metropolitan Region (CMR), Sri Lanka, Building and Environment, 40(12), 1591-1601.

Fanger P.O. (1970), Thermal Comfort, Danish Technical Press, Copenhagen, 244 pp.

Gagge A., Stolwijk A. and Nishi Y. (1971), An effective temperature scale based on a simple model of human physiological regulatory response, ASHRAE Trans, 77, 247-57.

Heisler G.M. and Wang Y. (2002), Applications of a Human Thermal Comfort Model. In: preprints of Fourth Symposium on the Urban Environment, 20-24 May 2002, Norfolk, VA, Sponsored by the American Meteorological Society, Boston, MA.

Honjo T. and Takakura T. (1990/91), Simulation of thermal effects of urban green areas on their surrounding areas, Energy and Buildings, 15-16, 457-463.

Höppe P. (1984), Die Energiebilanz des Menschen, Wiss Mitt Meteorol Inst Univ München No. 49.

Höppe P. (1993), Heat balance modelling, Experientia, 49, 741-746.

Höppe P. (1999), The physiological equivalent temperature - a universal index for the biometeorological assessment of the thermal environment, International Journal of Biometeorology, 43, 71-75.

Kyle W.J. (1994), The human bioclimate of Hong Kong, Proceedings of the Contemporary Climatology Conference, 345-350 pp.

Lee R. (1978), Forest Microclimatology, Columbia University Press, New York, NY, 276 pp.

Matzarakis A., Rutz F. and Mayer H. (2000) Estimation and calculation of the mean radiant temperature within urban structures. In: Biometeorology and Urban Climatology at the Turn of the Millenium (ed. by R.J. de Dear, J.D. Kalma, T.R. Oke and A. Auliciems): Selected Papers from the Conference ICB-ICUC'99, Sydney, WCASP-50, WMO/TD No. 1026, 273-278.

Matzarakis A., Rutz F. and Mayer H. (2007), Modelling Radiation fluxes in simple and complex environments - Application of the RayMan model, International Journal of Biometeorology, 51, 323334.

Matzarakis A. and Rutz F. (2005), Application of RayMan for tourism and climate investigations, Annalen der Meteorologie, 41 (2), 631-636.

McPherson E.G., Nowak D.J. and Rowntree R.A (1994), Chicago's urban forest ecosystem: Results of the chicago urban forest climate project. USDA forest service, General Technical report NE-186 pp.

Myrup L.O., McGinn C.E. and Flocchini R.G. (1993), An analysis of microclimatic variation in a suburban environment, Atmos. Environment, 27(B), 129-156. 
Rudel E., Matzarakis A. and Koch E. (2007), Summer Tourism in Austria and Climate Change. In: Oxley, L. and Kulasiri, D. (eds) MODSIM 2007 International Congress on Modelling and Simulation. Modelling and Simulation Society of Australia and New Zealand, December 2007, pp. 1934-1939. ISBN: 978-0-9758400-4-7.

Oke T.R. (1987), Boundary Layer Climates, William Clowes and Sons Limited, London, 372 pp.

Oke T.R. (1989), The micrometeorology of the urban forest, Phil. Trans. Royal Society London B, 324, 335-349.

Schiller G. (2001), Biometeorology and recreation in east Mediterranean forests, Landscape and Urban Planning, 57 (1), 1-12.

Scott K.I., Simpson J.R. and McPherson E.G. (1999), Effects of tree cover on parking lot microclimate and vehicle emissions, Journal of Arboriculture, 25(3), 129-142.

Scott D., McBoyle G. and Schwartzentruber M. (2004), Climate change and the distribution of climatic resources for tourism in North America, Clim Res., 27, 105-117.

Shashua-Bar L. and Hoffman M.E. (2000), Vegetation as a climatic component in the design of an urban street, Energy and Buildings, 31, 221-235.

Shashua-Bar L. and M.E. Hoffman (2004), Quantitative evaluation of passive cooling of the UCL microclimate in hot regions in summer, case study: urban streets and courtyards with trees, Building and Environment, 39, 1087-1099.

Simpson J.R., Levitt D.G., Grimmond C.S.B., McPherson E.G. and Rowntree R.A. (1994), Effects of vegetative cover on climate, local scale evaporation and air conditioning energy use in urban southern California, pp 345-348. In 11th Conference on Biometeorology and Aerobiology, March 7-11, 1994, San Diego, CA, American Meteorological Society.

Spangenberg J. (2004), Improvement of Urban Climate in Tropical Metropolis - A case study in Maracanã/ Rio de Janeiro, Thesis (Master in architecture), University of Applied Sciences, Cologne, Germany.

Spangenberg J., Shinzato P., Johansson E. and Duarte D. (2008), Simulation of the influence of vegetation on microclimate and thermal comfort in the city of Sao Paulo, Rev. SBAU, Piracicaba, 3(2), 1-19.

Streiling S. and Matzarakis A. (2003), Influence of single and small clusters of trees on the bioclimate of a city: A case study, Journal of Arboriculture, 29(6), 309-316.

Taha H. (1997), Urban climates and heat islands: albedo, evapotranspiration, and anthropogenic heat, Energy and Buildings, 25, 99-103.

Thom E.C. (1959), The discomfort index, Weatherwise, 12, 57-60.

Toy S., Yilmaz S. and Yilmaz H. (2007), Determination of bioclimatic comfort in three different land uses in the city of Erzurum, Turkey, Building and Environment, 42(3), 1315-1318

Toy S. and Yilmaz S. (2010), Thermal sensation of people performing recreational activities in shadowy environment: a case study from Turkey, Theoredical and Applied Climatology, 101(3-4), 329-343.

Toy S. and Yilmaz S. (2010a), Evaluation of urban - rural bioclimatic comfort differences over a ten - year period; in the sample of Erzincan city reconstructed after a heavy earthquake, Atmósfera, 23(4), $387-402$

Unger J. (1999), Urban - Rural Air Humidity Differences in Szeged, Hungary, International Journal of Climatology, 19, $1509-1515$.

Yilmaz H. and Irmak M.A. (2004), Evaluating Plant Materials Used in Open-Green Areas in Erzurum, Journal of Ecology, 13(52), 9-16.

Yilmaz S., Toy S., Irmak M.A. and Yilmaz H. (2007), Determination of climatic differences in three different land uses in the city of Erzurum, Turkey, Building and Environment, 42(4), 1604-1612. 